Supporting Information for

\title{
Structure-Based Discovery of Novel Nonpeptide Inhibitors Targeting SARS-CoV-2 Mpro
}

\author{
Jingyi Yang ${ }^{1 \dagger}$, Xiaoyuan $\mathrm{Lin}^{2 \dagger}$, Na Xing ${ }^{3 \dagger}$, Zhao Zhang ${ }^{1}$, Haiwei Zhang ${ }^{4}$, Haibo $\mathrm{Wu}^{2 *}$, \\ Weiwei Xue ${ }^{*}$
}

\begin{abstract}
${ }^{1}$ School of Pharmaceutical Sciences and Innovative Drug Research Centre, Chongqing Key Laboratory of Natural Product Synthesis and Drug Research, Chongqing University, Chongqing 401331, China

${ }^{2}$ School of Life Sciences, Chongqing University, Chongqing 401331, China

${ }^{3}$ Institut für Virologie, Freie Universität Berlin, Berlin 14163, Germany

${ }^{4}$ Chongqing Key Laboratory of Translational Research for Cancer Metastasis and Individualized Treatment, Chongqing University Cancer Hospital, Chongqing 401331, China
\end{abstract}

\section{*Corresponding Authors}

Dr. Weiwei Xue

Email: xueww@cqu.edu.cn

Dr. Haibo $\mathrm{Wu}$

Email: hbwu023@cqu.edu.cn

$\dagger$ J.Y., X.L. and N.X. contributed equally. 
Table S1. The selected top-ranked compounds that were predicted to bind the active site of SARSCoV-2 Mpro ensembles

\begin{tabular}{|c|c|c|c|c|}
\hline No. & IDs & $\mathrm{M}^{\text {pro }}$ ensembles $^{a}$ & GlideScore $^{b}$ & Chemical structures \\
\hline 1 & Z1148237891 & 6LU7_2us & -7.511 & \\
\hline 2 & Z595842248 & 6LU7_2us & -7.417 & \\
\hline 3 & Z1455656891 & 6LU7_2us & -7.437 & \\
\hline 4 & Z1797022964 & 6LU7_2us & -8.528 & \\
\hline 5 & Z1657751358 & 6LU7_2us & -7.544 & \\
\hline 6 & Z1754384966 & 6LU7_2us & -8.087 & \\
\hline 7 & Z1798238306 & 6LU7_4us & -8.14 & \\
\hline 8 & Z236230776 & 6LU7_4us & -7.343 & \\
\hline
\end{tabular}




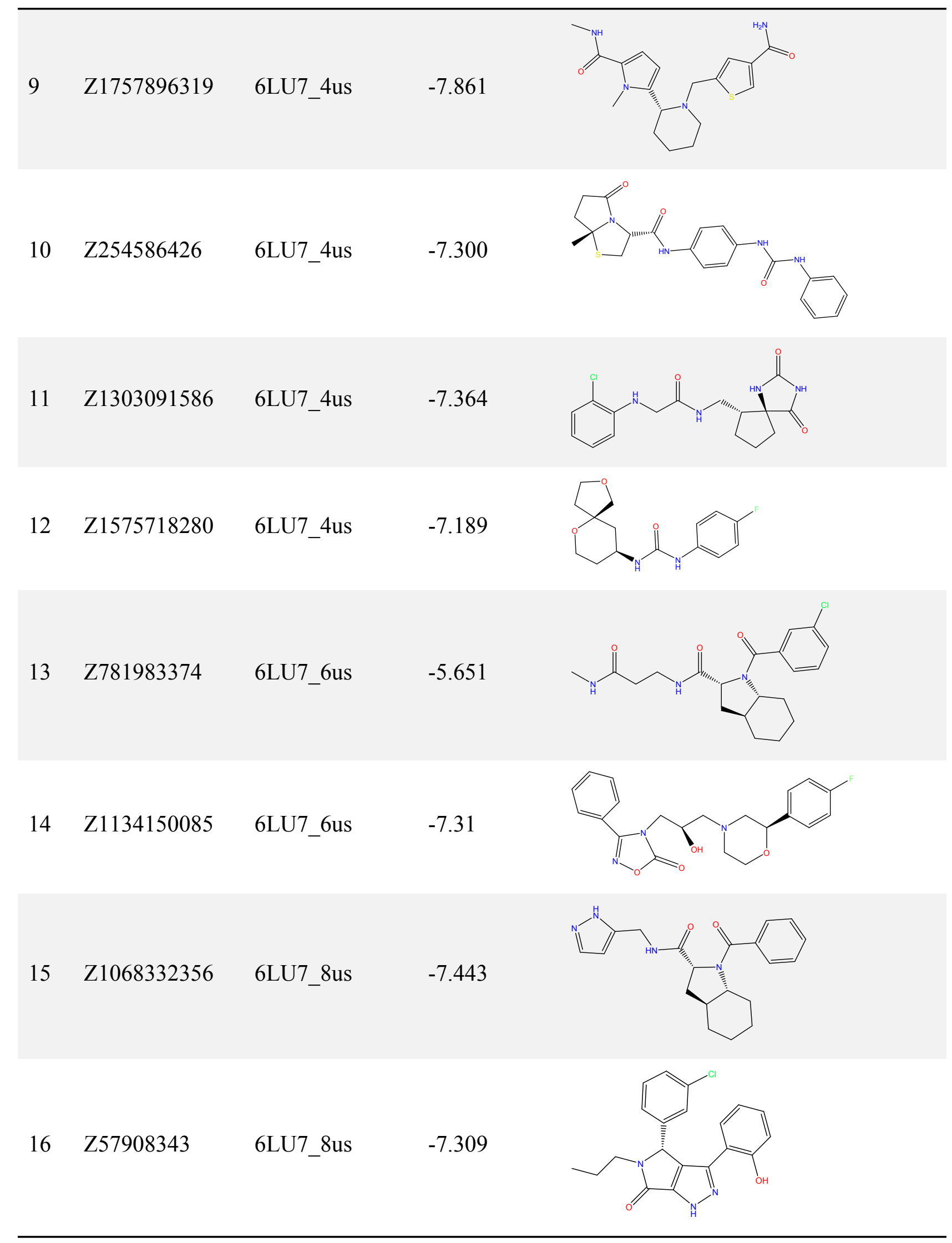




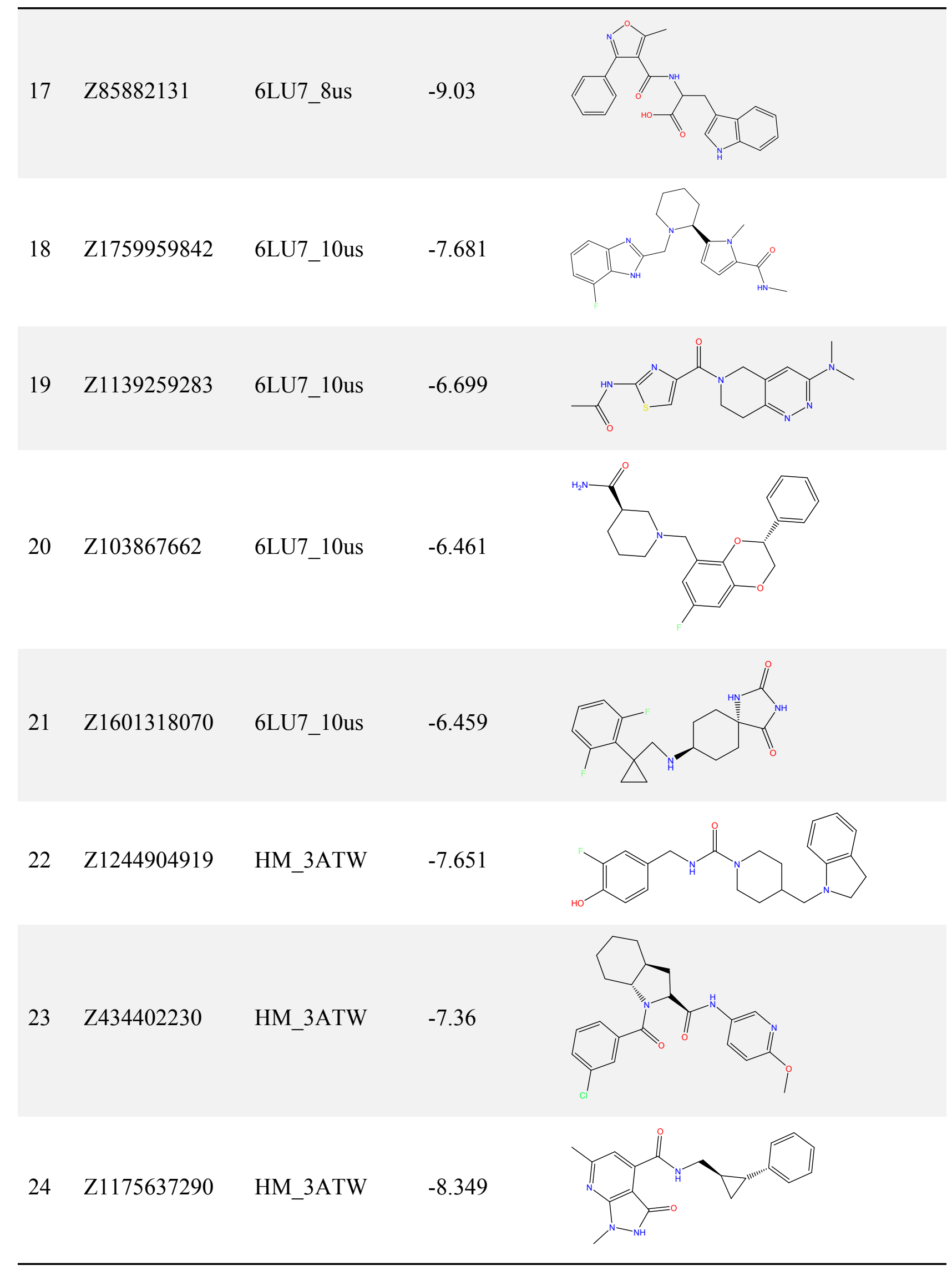




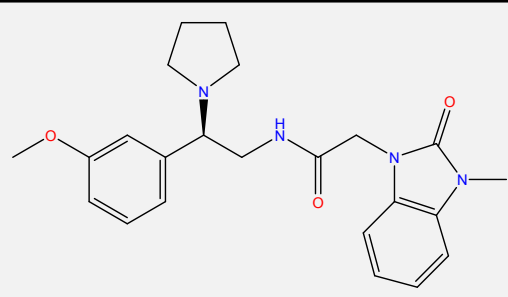

$26 \quad$ Z954310956 6LU7

$-8.823$

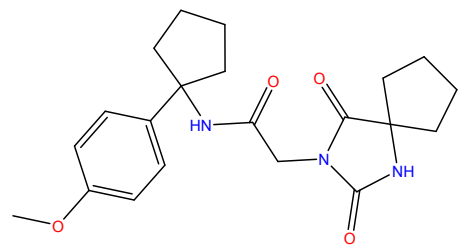

$27 \quad$ Z1338140894

6LU7

$-8.362$

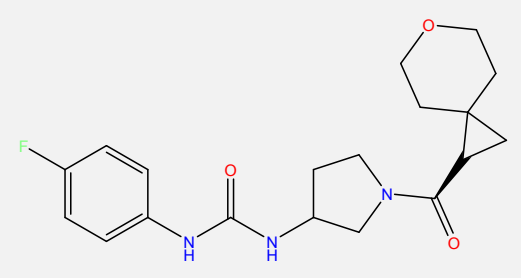

$28 \quad$ Z812501892

6LU7

$-8.521$

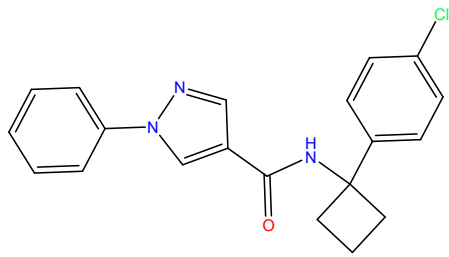

$29 \quad$ Z220618026

6LU7

$-9.285$

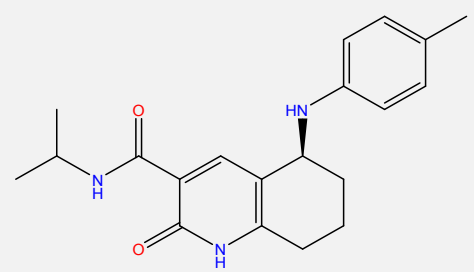

$30 \quad Z 98332453$

6LU7

$-8.844$

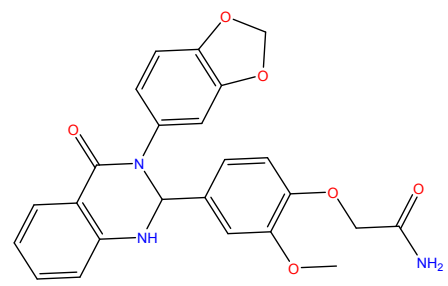

$31 \quad$ Z424991624

6LU7

$-8.648$

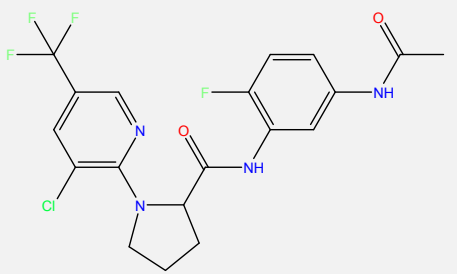


$32 \quad$ Z109826290 6LU7

$-8.904$

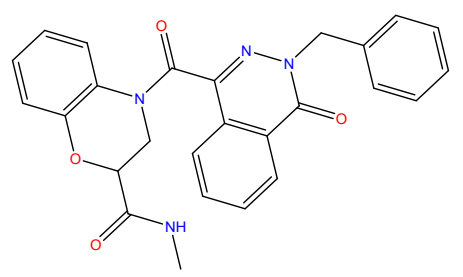

$33 \quad$ Z73433619

6LU7

$-8.427$

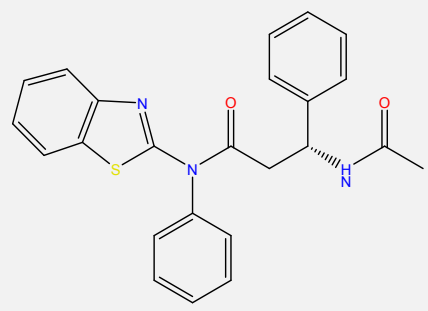

$34 \quad$ Z355472054 $\quad 6 L U 7$

$-9.244$

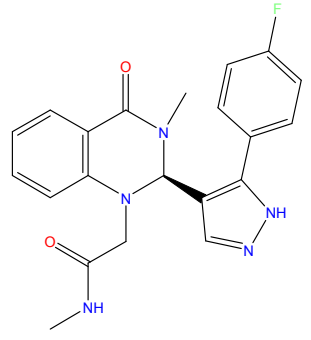

$35 \quad$ Z363119456 $\quad 6 L U 7$

$-9.277$

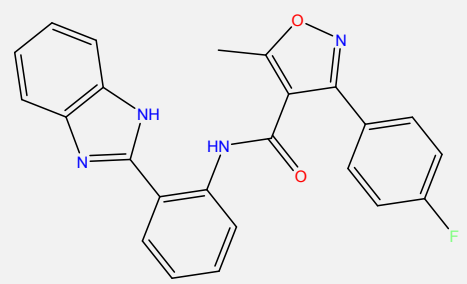

$36 \quad \mathrm{Z} 1233804881 \quad 6 \mathrm{Y} 2 \mathrm{~F}$

$-8.838$

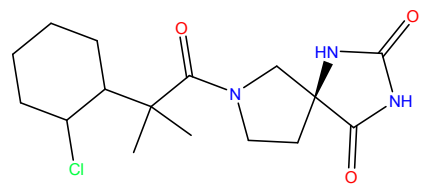

$37 \quad \mathrm{Z} 225729516 \quad 6 Y 2 F$

$-8.502$

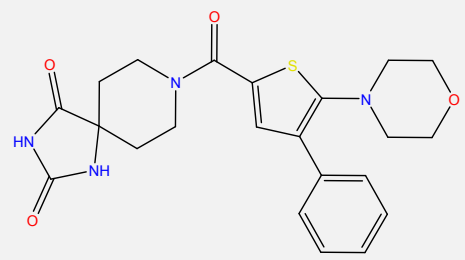

$38 \quad$ Z225722720 $\quad 6 Y 2 F$

$-8.372$

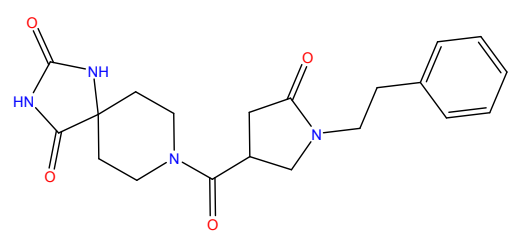




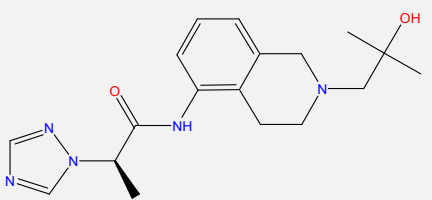

$40 \quad \mathrm{Z} 1759961356 \quad 6 \mathrm{Y} 2 \mathrm{~F}$

$-8.332$

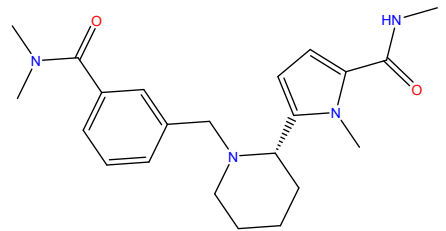

41

$6 \mathrm{Y} 2 \mathrm{~F}$

$-8.718$

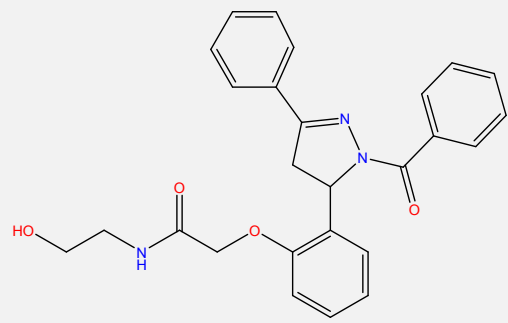

42

$6 \mathrm{Y} 2 \mathrm{~F}$

$-8.379$

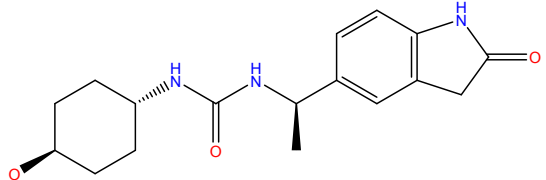

43

$6 \mathrm{Y} 2 \mathrm{~F}$

$-8.818$

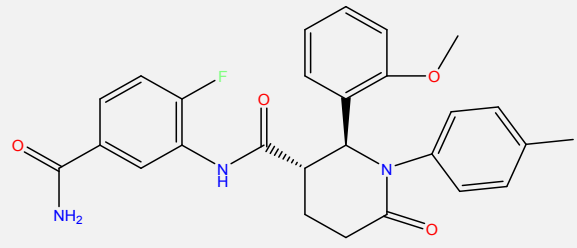

$44 \quad$ Z225731922 $6 Y 2 G$

$-8.657$

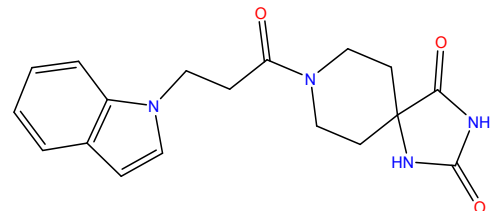

$45 \quad \mathrm{Z} 979255430 \quad 6 Y 2 \mathrm{G}$

$-8.651$

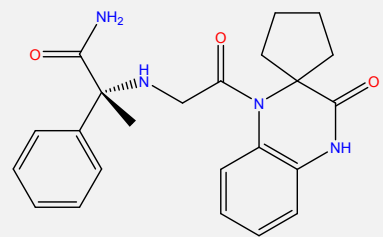

$46 \quad$ Z1391059752 6Y2G

$-8.049$

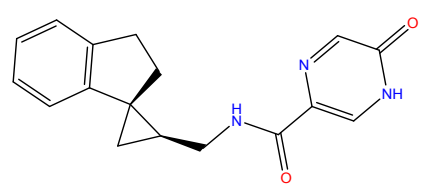




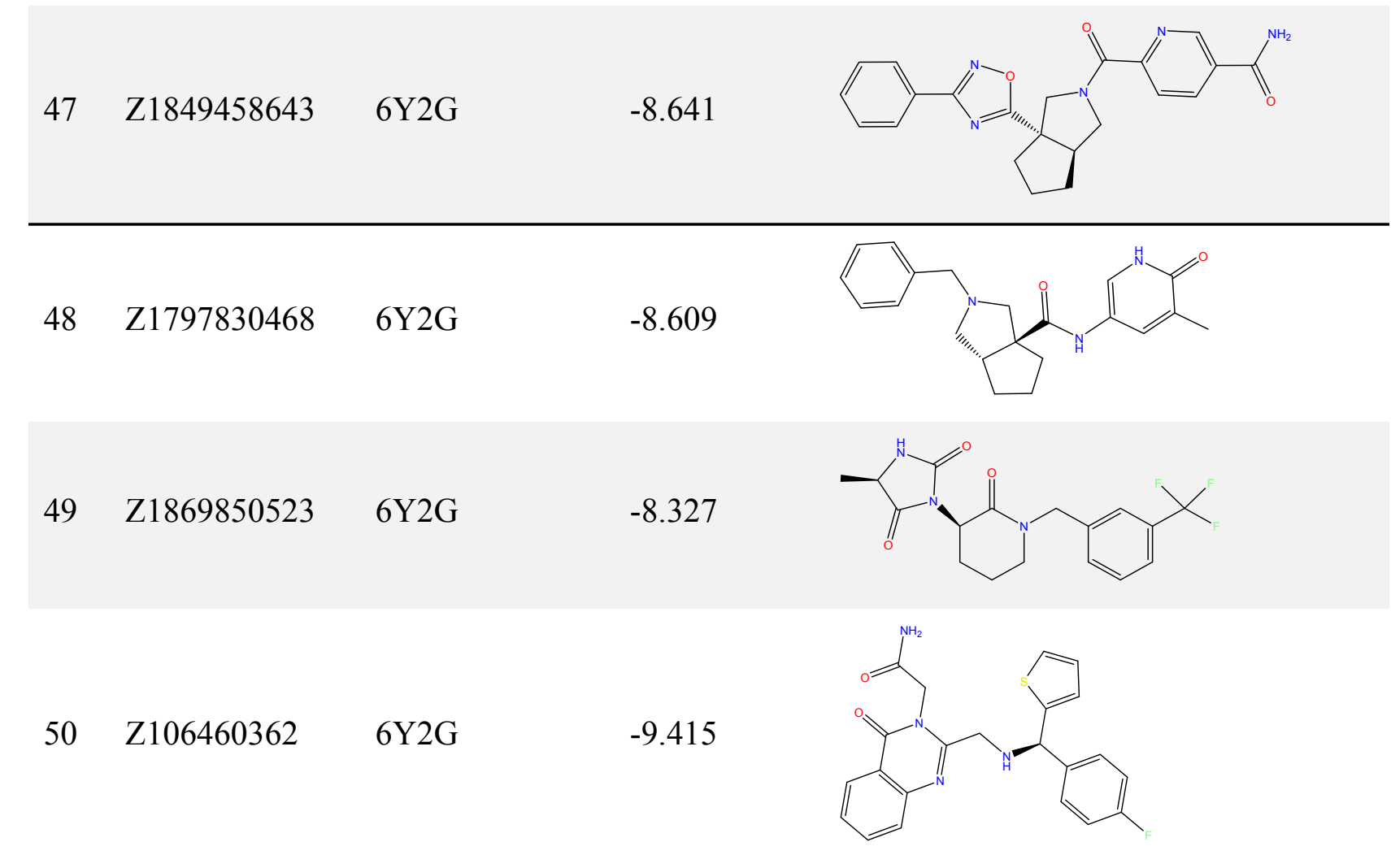

${ }^{a}$ The nine SARS-CoV-2 $\mathrm{M}^{\text {pro }}$ structures including five apo forms (extracted per $2 \mu$ s from $10 \mu \mathrm{sD}$ simulation of $6 \mathrm{LU}^{1,2}$ ) and the four holo forms (one homology model using $3 \mathrm{ATW}^{3}$ as a template and three crystal structures $6 \mathrm{LU} 7^{1}, 6 \mathrm{Y}^{2} \mathrm{~F}^{1}$ and $6 \mathrm{Y}^{2} \mathrm{G}^{4}$ in complex with different ligands. ${ }^{b}$ The docking score $(\mathrm{kcal} / \mathrm{mol})$ were calculated by Glide extra precision algorithm 5 . 
Table S2. The values of energy contribution of identified key residues in Z1244904919-M ${ }^{\text {pro }}$ and Z1759961356-M ${ }^{\text {pro }}$ complexes

\begin{tabular}{|c|c|c|c|}
\hline \multicolumn{2}{|c|}{ Z1244904919-Mpro } & \multicolumn{2}{|c|}{ Z1759961356-M pro } \\
\hline Residue & Energy & Residue & Energy \\
\hline Thr25 & -0.56 & Leu27 & -0.74 \\
\hline Leu 27 & -0.97 & His41 & -2.49 \\
\hline His41 & -2.04 & Glu47 & -1.76 \\
\hline Met 49 & -1.04 & Met49 & -0.51 \\
\hline Phe140 & -0.63 & Leu50 & -0.56 \\
\hline Leu 141 & -1.3 & Cys 145 & -0.86 \\
\hline Asn 142 & -2.58 & His 164 & -1.18 \\
\hline Gly 143 & -1.44 & Met165 & -2.99 \\
\hline Ser144 & -1.39 & Val186 & -0.6 \\
\hline Cys145 & -2.39 & Asp187 & -1.37 \\
\hline His164 & -0.68 & Arg188 & -1.09 \\
\hline Met165 & -1.12 & Gln189 & -1.99 \\
\hline Glu166 & -0.89 & Gln192 & -1.67 \\
\hline Gln189 & -0.68 & & \\
\hline
\end{tabular}


Table S3. Summary of the origin as well as the size of the nine grid boxes used for docking

\begin{tabular}{llll}
\hline M pro ensembles & Grid center & Inner box $(\AA)$ & Outer box $(\AA)$ \\
\hline 6LU7_2us & $59.58,50.73,69.32$ & $10,10,10$ & $30,30,30$ \\
6LU7_4us & $59.58,50.73,69.32$ & $10,10,10$ & $30,30,30$ \\
6LU7_6us & $59.58,50.73,69.32$ & $10,10,10$ & $30,30,30$ \\
6LU7_8us & $59.58,50.73,69.32$ & $10,10,10$ & $30,30,30$ \\
6LU7_10us & $59.58,50.73,69.32$ & $10,10,10$ & $30,30,30$ \\
HM_3ATW & $-6.41,2.10,-16.62$ & $10,10,10$ & $25.89,25.89,25.89$ \\
6LU7 & $-10.50,12.38,68.87$ & $10,10,10$ & $32.10,32.10,32.10$ \\
6Y2F & $-10.59,13.02,67.97$ & $10,10,10$ & $27.78,27.78,27.78$ \\
6Y2G & $-10.71,12.90,68.17$ & $10,10,10$ & $27.57,27.57,27.57$ \\
\hline
\end{tabular}




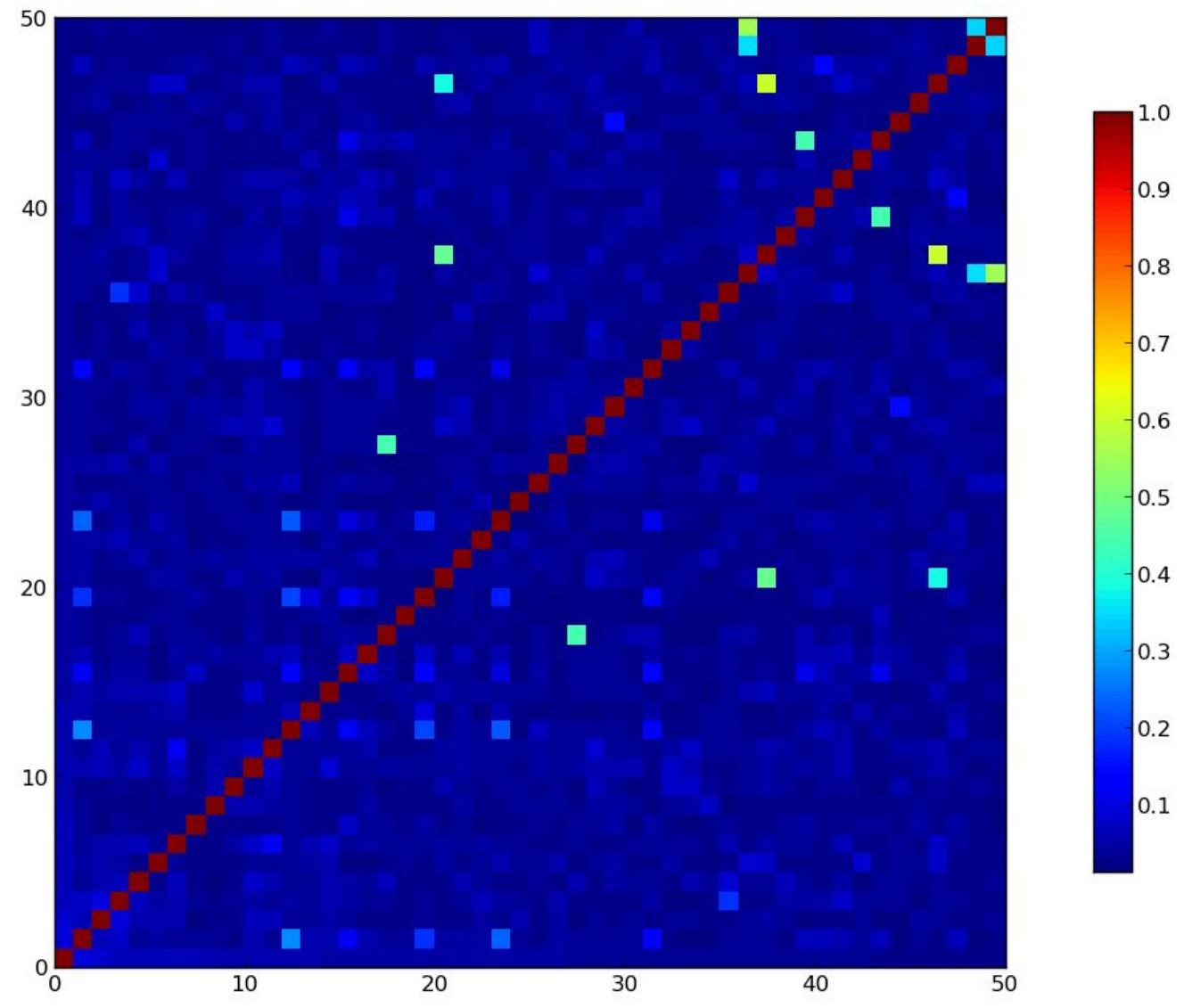

Figure S1. The result of scaffold diversity profiles of selected compounds analyzed by hierarchical clustering of the fingerprints using Tanimoto similarity and Ward's cluster linkage method ${ }^{6}$. The X and $\mathrm{Y}$ axis represent the number of the selected 50 compounds. 


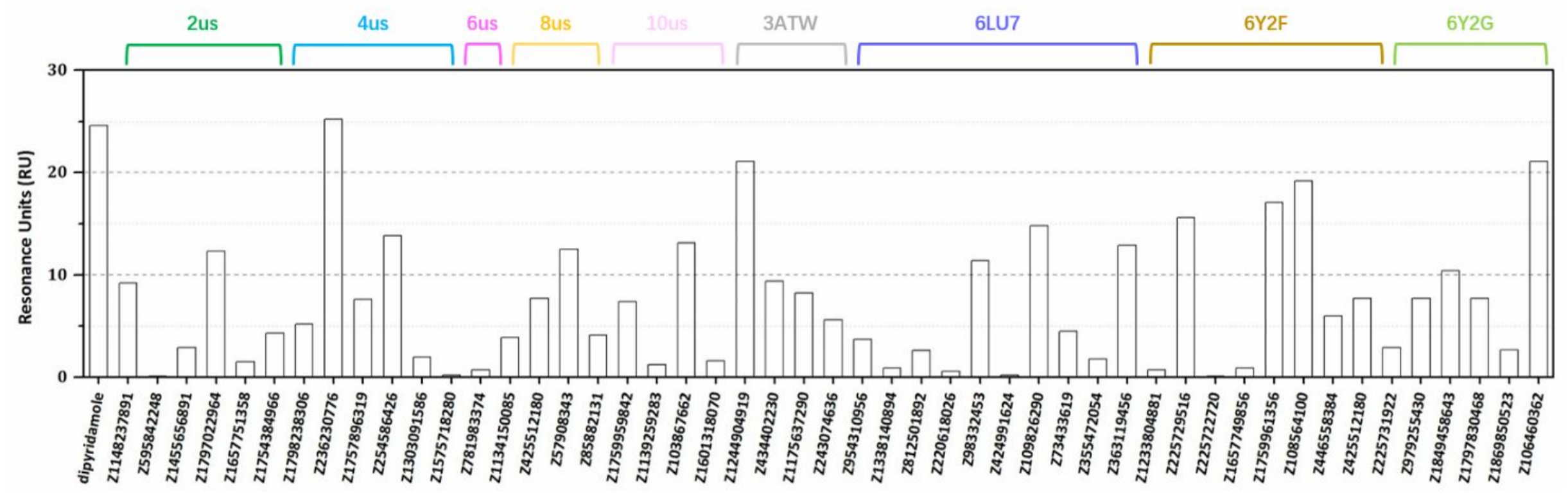

Figure S2. Binding properties of 49 computationally selected compounds at SARS-CoV-2 main protease (M ${ }^{\text {pro }}$ ). The binding of compound was revealed by resonance units (RU) in the presence of each candidate at a concentration of $100 \mu \mathrm{M}$. DIP was used as a positive control. 


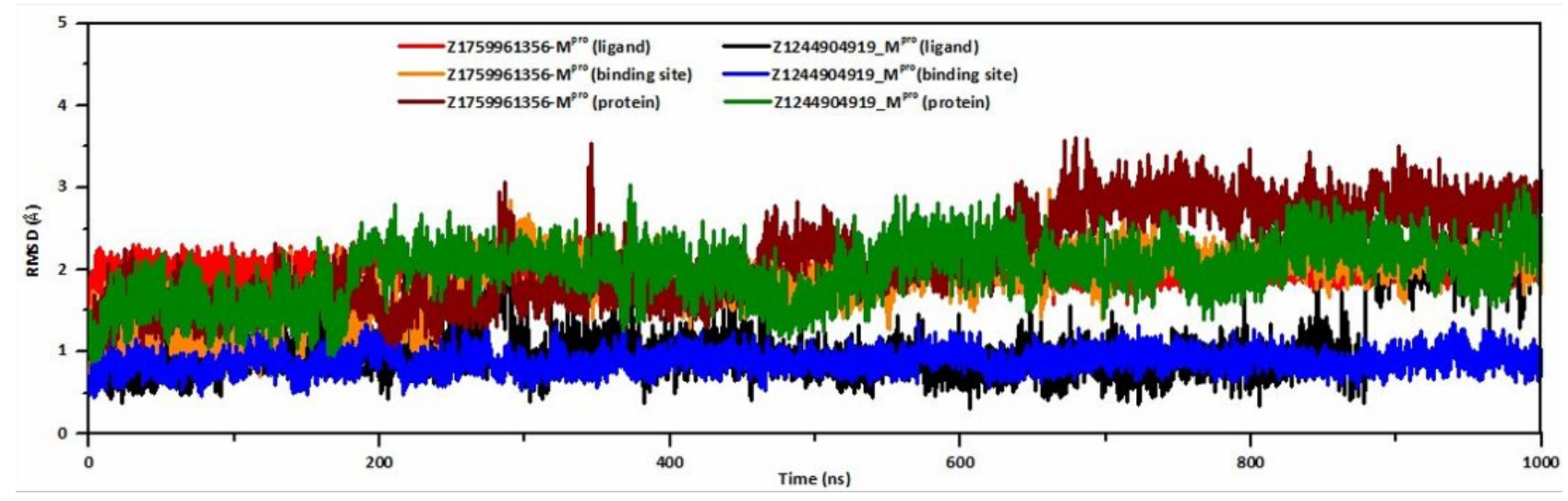

Figure S3. The time evolution of the root-mean-square deviation (RMSD) of backbone atoms of protein and heavy atoms of ligand for each binding complex with respective to the initial coordinates. 
(A)

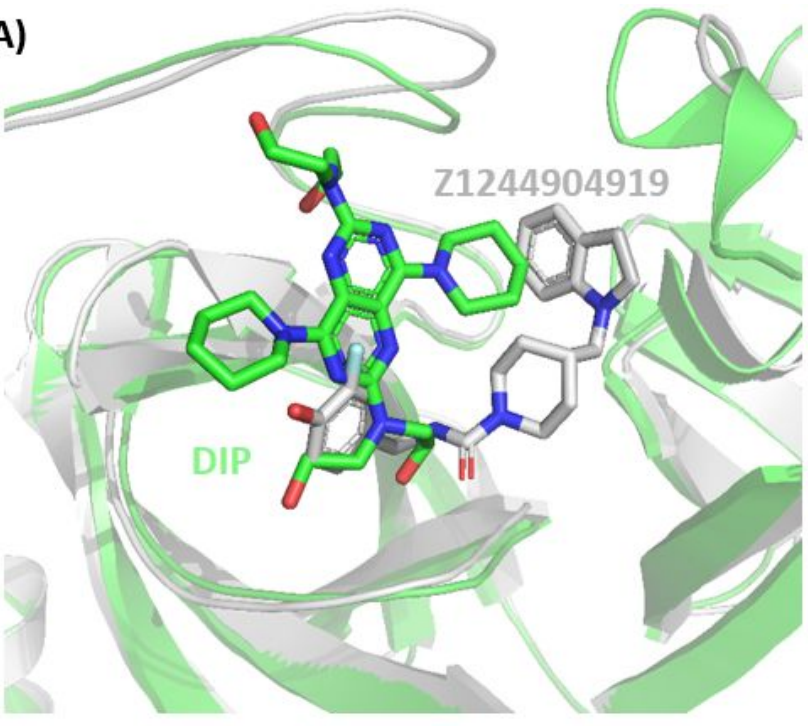

(C)

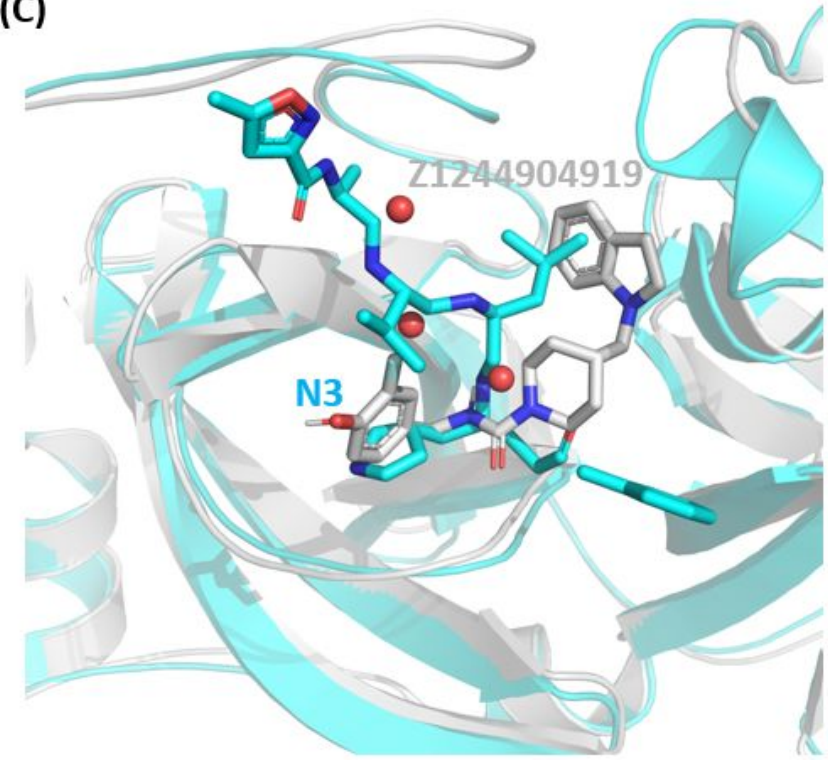

(B)

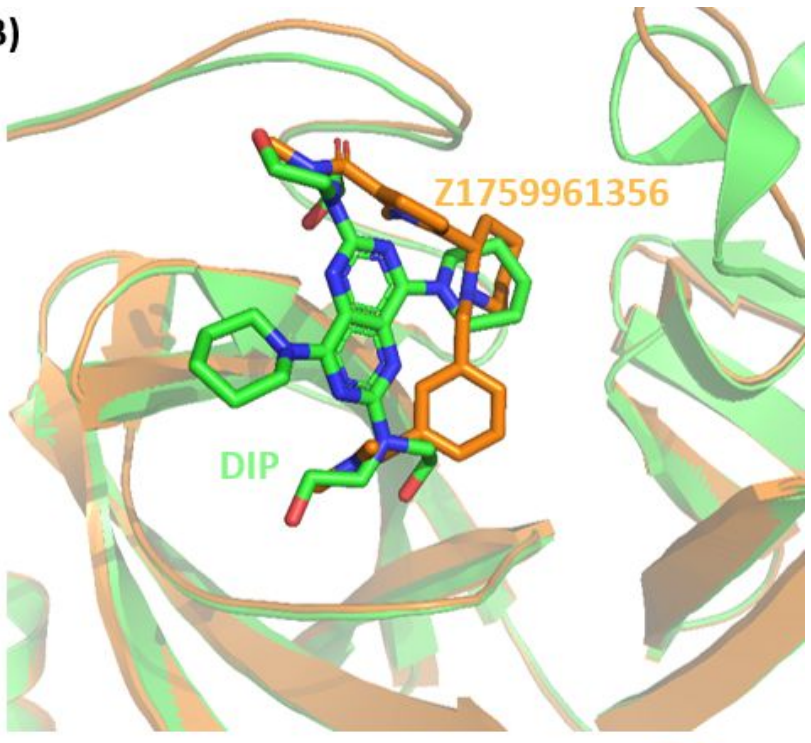

(D)

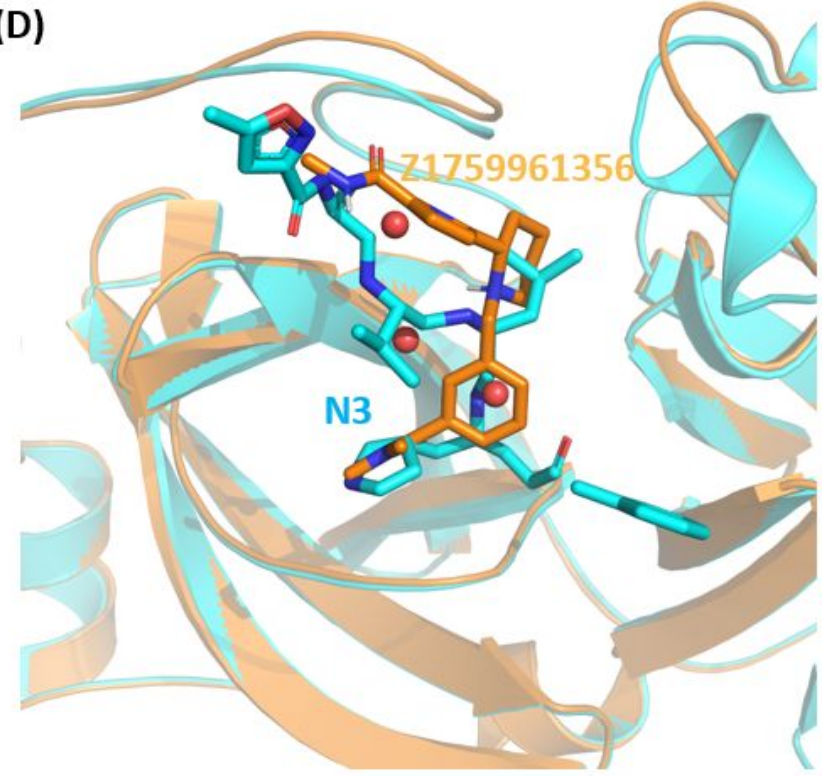

Figure S4. The superposition between SARS-CoV-2 Mpro in complex with DIP and Z1244904919 (A) and ZN1759961356 (B), N3 and Z1244904919 (C) and ZN1759961356 (D). The protein and ligand were displayed as cartoon and stick representation, respectively. 
(A)

\begin{tabular}{|c|l|l|}
\hline substrate & Z1244904919 & Z1759961356 \\
\hline Leu27 & & \\
\hline Ser46 & & \\
\hline Met49 & & \\
\hline Phe140 & & \\
\hline Asn142 & & \\
\hline Gly143 & & \\
\hline Ser144 & & \\
\hline Cys145 & & \\
\hline His163 & & \\
\hline Met165 & & \\
\hline Glu166 & & \\
\hline Pro168 & & \\
\hline His172 & & \\
\hline Arg188 & & \\
\hline GIn189 & & \\
\hline
\end{tabular}

(B)

\begin{tabular}{|c|c|c|}
\hline N3 & Z1244904919 & Z1759961356 \\
\hline His41 & & \\
\hline Phe140 & & \\
\hline Asn142 & & \\
\hline Gly143 & & \\
\hline Cys145 & & \\
\hline His163 & & \\
\hline His164 & & \\
\hline Glu166 & & \\
\hline GIn189 & & \\
\hline Thr190 & & \\
\hline GIn192 & & \\
\hline
\end{tabular}

Figure S5. The common interaction residues of Z1244904919 and Z1759961356 (filled with green color) in this study with the substrate ${ }^{7}$ and peptide-like inhibitor $N 3^{8}$ reported by Swiderek and Moliner group. 


\section{References}

(1) Jin, Z.; Du, X.; Xu, Y.; Deng, Y.; Liu, M.; Zhao, Y.; Zhang, B.; Li, X.; Zhang, L.; Peng, C.; Duan, Y.; Yu, J.; Wang, L.; Yang, K.; Liu, F.; Jiang, R.; Yang, X.; You, T.; Liu, X.; Yang, X.; Bai, F.; Liu, H.; Liu, X.; Guddat, L. W.; Xu, W.; Xiao, G.; Qin, C.; Shi, Z.; Jiang, H.; Rao, Z.; Yang, H. Structure of M(pro) from SARS-CoV-2 and discovery of its inhibitors. Nature 2020, 582, 289-293.

(2) KOMATSU, T. S.; ; Koyama, Y.; ; OKIMOTO, N.; ; MORIMOTO, G.; ; Ohno, Y.; ; Taiji, M. COVID-19 related trajectory data of 10 microseconds all atom molecular dynamics simulation of SARS-CoV-2 dimeric main protease. Mendeley Data 2020.

(3) Akaji, K.; Konno, H.; Mitsui, H.; Teruya, K.; Shimamoto, Y.; Hattori, Y.; Ozaki, T.; Kusunoki, M.; Sanjoh, A. Structure-based design, synthesis, and evaluation of peptide-mimetic SARS 3CL protease inhibitors. Journal of Medicinal Chemistry 2011, 54, 7962-73.

(4) Zhang, L.; Lin, D.; Sun, X.; Curth, U.; Drosten, C.; Sauerhering, L.; Becker, S.; Rox, K.; Hilgenfeld, R. Crystal structure of SARS-CoV-2 main protease provides a basis for design of improved alpha-ketoamide inhibitors. Science 2020, 368, 409-412.

(5) Friesner, R. A.; Banks, J. L.; Murphy, R. B.; Halgren, T. A.; Klicic, J. J.; Mainz, D. T.; Repasky, M. P.; Knoll, E. H.; Shelley, M.; Perry, J. K.; Shaw, D. E.; Francis, P.; Shenkin, P. S. Glide: a new approach for rapid, accurate docking and scoring. 1. Method and assessment of docking accuracy. Journal of Medicinal Chemistry 2004, 47, 1739-49.

(6) Sastry, M.; Lowrie, J. F.; Dixon, S. L.; Sherman, W. Large-scale systematic analysis of 2D fingerprint methods and parameters to improve virtual screening enrichments. Journal of Chemical Information and Modeling 2010, 50, 771-784.

(7) Katarzyna Świderek, V. M. Revealing the molecular mechanisms of proteolysis of SARS-CoV-2 Mpro by QM/MM computational methods. Chmical Science 2020, 11, 10626-10630.

(8) Kemel Arafet, N. S.-A., Alessio Lodola, Adrian J. Mulholland, Florenci V. González, Katarzyna Świderek and Vicent Moliner Mechanism of inhibition of SARS-CoV-2 Mpro by N3 peptidyl Michael acceptor explained by $\mathrm{QM} / \mathrm{MM}$ simulations and design of new derivatives with tunable chemical reactivity. Chmical Science 2021, 12, 1433-1444. 